\title{
Effect of adding powder on joint properties of laser penetration welding for dual phase steel and aluminum alloy
}

\author{
Zhou D W*, Liu J S, Lu Y Z, Xu S H \\ State Key Laboratory of Advanced Design and Manufacturing for Vehicle Body, Hunan \\ University, Changsha 410082, China
}

\begin{abstract}
:
The experiments of laser penetration welding for dual phase steel and aluminum alloy were carried out, and the effect of adding Mn or Si powder on mechanical properties and microstructure of the weld was investigated. Some defects, such as spatter, inclusion, cracks and softening in heat affected zone (HAZ), can be avoided in welding joints, and the increased penetration depth is obtained by adding $\mathrm{Mn}$ or $\mathrm{Si}$ powder. The average tensile-shear strength of Si-added joint is 3.84\% higher than that of Mn-added joint, and the strength of both joints exceeds that of no-added joint. In the case of adding Mn powder, small amount of liquid Al is mixed into steel molten pool, and the Al content increases in both sides of the weld, which leads to the increased weld width in aluminum molten pool. Thus, transverse area increases in jointing steel to aluminum, which is significant for the improved tensile-shear strength of joints. As far as adding Si powder is concerned, it is not the case, the enhancement of the joint properties benefits from improvement of metallurgical reaction.
\end{abstract}

Key words: Laser penetration welding; Powder;Microstructure;Mechanical properties

\section{Introduction}

${ }^{*}$ Corresponding author.Tel.:+86 13017297124;fax.:+86 7318821483.

E-mail address: ZDWe_mail@126.com(D.W.Zhou)

$-1-$

(C) 2016. This manuscript version is made available under the Elsevier user license http://www.elsevier.com/open-access/userlicense/1.0/ 
Recently, there has been an increasing demand for light weight and high specific strength materials in the automotive industry due to fuel consumption and protecting environment [1]. Joining steel to aluminum has been recognized as one of the major measures[2-8]. However, it is difficult for welding of steel and aluminium because a number of brittle intermetallic compounds(IMCs) are easily formed during welding. Laser welding can shorten the metallurgical reaction time and restrict the formation of IMCs with high heating and cooling rates. Sierra et al. [5] suggested a steel-on-aluminium overlap configuration, and thought the formation of IMCs is suppressed effectively by controlling steel penetration in aluminium. Later, various researchers have been stepping up efforts to join steel to aluminum by using this method [9-11]. However, these investigations only optimized the joint properties with respect to process parameters or heat source.

Improving the metallurgical reaction is an effective way of enhancing the joint properties. Usually, adding an interlayer can improve the metallurgical reaction of molten pool for laser welding. In our primary investigation, it was found that adding $\mathrm{Pb}$-foil interlayer can improve the mechanical properties of the laser welding joint in steel-on-aluminium overlap configuration[12]. Chen et al.[13,14] showed that when Ni-foil was added at the welding interface of steel and aluminum, similarly, the joint properties is also improved. Yang et al. [15] investigated laser welding steel to aluminum with $\mathrm{Cu}$-foil, and found that $\mathrm{Cu}$-foil inhibits the $\mathrm{Al}$ diffusion to the steel side, but the joint strength is not improved. In this paper, the experiments of laser penetration welding for dual phase steel and aluminum alloy were carried out, and the 
effect of adding Mn or Si powder on mechanical properties and microstructure of the weld was investigated. The strengthening mechanism of the joint was clarified.

\section{Materials and experimental procedure}

The materials used in the experiment are 6016 aluminum alloy with composition of Al-1.2Si-0.4Mg-0.5Fe-0.2Mn(wt.\%), and DP590 dual phase steel with composition of $\mathrm{Fe}-0.15 \mathrm{C}-0.6 \mathrm{Si}-2.5 \mathrm{Mn}(\mathrm{wt} . \%)$. The sizes of them are $100 \times 30 \times 1.2 \mathrm{~mm}$ and $100 \times 30 \times 1.4 \mathrm{~mm}$, respectively. Steel sheet is placed on aluminum in an overlap configuration due to aluminum with high reflectivity. Mn or Si powder, with $99.9 \%$ purity, $75-\mu \mathrm{m}$ average size, and $0.1 \mathrm{~mm}$ thick is added between the two plates as interlayer, as shown in Fig.1.

Welding heat source is provided by YLS-4000-CL fiber laser, main laser technical parameters are shown in Table 1. Prior to welding, the surfaces of sheet samples are cleaned with acetone to remove grease and residues. Sandpaper is used to remove the oxide layer of aluminum alloy surface, $\mathrm{Mn}$ or Si powder is distributed evenly on the aluminum surface by using acetone. When it is dry, laser lap welding test is made. Laser beams are endicularly incident to upper surface. The protective gas is argon which is used to protect the front and back of weld at the same time. Deep penetration laser welding test with $\mathrm{Mn}$ or Si powder is carried out to obtain a good weld not only a weld with sufficient penetration but also an acceptable weld surface. The optimal process parameters are determined as follows: welding power is $2000 \mathrm{~W}$, welding speed is $50 \mathrm{~mm} / \mathrm{s}$, the defocus distance is $+2 \mathrm{~mm}$, and the rate of flow of the Ar protective gas is $15 \mathrm{~L} / \mathrm{min}$. The process parameters of adding powder are the same 
as that of no powder in order to identify the effect of adding powder on microstructure and properties of the weld.

After welding, test specimens are cut, then, standard metallographic preparation procedures are utilized. Microstructure, fracture morphology and interface elements distribution of the welds are performed by FEI Quanta 200 scanning electron microscopy equipped with spectrometer (EDS) and electron back-scattered diffraction (EBSD) probe. Crystalline phase of joints are identified by X-ray diffraction (XRD). Both tensile and shear forces are applied to the interface during test due to nonsymmetric configuration of the tensile test samples. Hence, in the current study, the joint strength is given in $\mathrm{N} / \mathrm{mm}$ (failure strength divided by the width of tested specimen) since it is difficult to separate tensile and shear stress. According to the BS EN 1002-1:2001 standard, the tensile-shear tests are operated at room temperature using INSTRON 5569 at a crosshead speed of $1 \mathrm{~mm} / \mathrm{min}$. Average joint strength is calculated from three tensile specimens.

\section{Results and discussion}

\subsection{Surface morphology and microstructure of joints}

Figure 2 shows the influence of adding powder on the surface morphology of joints. When Mn or Si powder is added, some defects, such as spatter, inclusion, cracks can be avoided under the condition of the optimized process. In addition, continuous uniform weld surface with rules pattern is easily observed. Further analysis for macro-morphologies of weld cross section is presented in Fig.3. Same thing happens, cracks and pores are also not obvious. The top of the molten pool is 
wide, while below is narrow, and the ratio of depth and width is bigger. An typical characteristics of "keyhole" finger can be seen. This exhibits welding mode is laser penetration welding in this study. However, when Mn or Si powder is added, welding penetration depth both increase compared with that of no-added joint, and the depth of Si-added joints exceeds that of Mn-added joints, which is shown in Fig.3a, Fig.3b, Fig.3c, respectively.

As is known, heat flux density is both determined by laser energy in laser penetration welding with/without powder, if welding parameters is kept the same, surface temperature of the upper dual phase steel should be not changed, but the lower aluminum alloy is affected by the air or powder layer. In normal conditions, thermal conductivity of the air is about $10^{-4}$ to $10^{-6} \mathrm{~W} /(\mathrm{mK})$, while that of the Fe-based or Al-base is about 10 to $10^{3} \mathrm{~W} /(\mathrm{mK})$. Consequently, air layer will hold back heat conduction, and decrease the cooling rate of joints. However, thermal conductivity of Mn or Si powder is higher than that of the air, when it replaces the air layer, the upper dual phase steel and the lower aluminum alloy will be connected tighly. As a result, blocked phenomenon of heat quantity is significantly improved, and heat quantity of the upper duel phase steel is quickly transferred to the lower aluminum alloy, thus the thermal conduction rate mounts up and the cooling rate of joint ascends. Hence, the increased welding penetration depth is obtained with the addition of powder.

In addition, laser energy absorption rate can be calculated by using the following expressions[16]:

$$
\alpha=0.365 \sqrt{\frac{\rho}{\lambda}}
$$


where $\alpha$ refers to laser energy absorption rate, $\rho$ and $\lambda$ are the resistivity and laser wavelength. Because laser welding process parameters of adding powder are the same as that of no powder, moreover, there are no change for laser wavelength, thus laser energy absorption rate depends upon the resistivity. In the case of no powder, laser energy absorption for the lower materials is determined by aluminum alloy sheet. While adding powder, laser energy absorption is affected by powder layer. Under normal circumstances, the resistivity of $\mathrm{Mn}$ or $\mathrm{Si}$ powder is higher than that of aluminum alloy, hence more laser energy is absorbed by the lower aluminium alloy with the addition of powder, which leads to the the increased welding penetration depth. Because the resistivity of Si is larger than that of Mn, thus adding Si powder is benefit for the absorption of laser energy, hence, the biggest welding penetration depth is found for Si-added joints(Fig.3c).

Figure 4 exhibits phase distribution and content of steel/aluminum weld with/without powder. It is found that microstructure of joints is mainly ferrite, martensite and a small amount of residual austenite, while bainite does not appear. In the case of adding $\mathrm{Mn}$ or Si powder, the content of ferrite and martensite are $73.9 \%$ and $25.8 \%, 75.9 \%$ and $23.0 \%$, respectively, which is shown in Fig. $4 \mathrm{c}$ and Fig.4d. As a comparison, the content of base metal of dual phase steel are $64.6 \%, 33.4 \%$, respectively, which is shown in Fig.4a. Hence, the results suggest that phase composition of the upper layer dual phase steel has not been damaged by the use of powder.

Figure 5 shows the influence of adding powder on microstructure of joints from 
the weld to the parent metal area. Columnar crystal grain can be seen for No-added joint(Fig.5a), and grain size is significantly larger than that of the parent metal. At the edge of the molten pool, grain size is about $50 \mu \mathrm{m}$. However, when Mn or Si powder is added, grain size is about $30 \mu \mathrm{m}$ or $45 \mu \mathrm{m}$, which is shown in Fig.5b, Fig.5c, respectively. Grain orientation and its size distribution of joints with/without powder are also analyzed, which is shown in Fig.6. As far as No-added joints is concerend, the average grain size is $41.91 \mu \mathrm{m}$, the distribution of grain size is the range of $1.5-76 \mu \mathrm{m}$ (Fig.6b). In the case of adding Mn powder, the average grain size is $34.92 \mu \mathrm{m}$, the distribution of grain size is located in the region of $25-35 \mu \mathrm{m}$ (Fig.6d). Thus the decreased grain size is seen for Mn-added joints. However, as far as adding Si powder is concerend, the average grain size is $41 \mu \mathrm{m}$, and the distribution of grain size lies to the range of $25-40 \mu \mathrm{m}$ (Fig.6f), which indicates that there is almost no change for grain size compared with that of No-added joints.

Figure 7 shows SEM image of No-added joint. Dual phase steel melted by laser beam heating is embedded into the melted aluminum which is shown in Fig.7a. It is found that some isolated particles are distributed at the interface zone, a severe interfacial reaction occurrs, and IMCs with thickness of about $20 \mu \mathrm{m}$ are formed between the fusion zone and aluminum alloy. To observe interfacial microstructure in detail, P1 zone in Fig.7a is magnified, as shown in Fig.7b. It is found that the reaction production is divided into three layers. To determine the phase compositions of IMCs, XRD and EDS are performed. Figure 8 shows the XRD patterns of No-added joint, in which it is seen that IMCs of $\mathrm{FeAl}$ and $\mathrm{FeAl}_{2}$ are formed at the reaction zones. Table 2 
shows the EDS results at the A-E zone in Fig.7b. It is found that at B zone the Al content is less, mainly for Fe. At $\mathrm{C}$ and $\mathrm{D}$ zone, the $\mathrm{Fe} / \mathrm{Al}$ ratio is very close to $1: 1$, 1:2, respectively.Thus $\mathrm{FeAl}$ and $\mathrm{FeAl}_{2}$ may be formed at $\mathrm{C}$ and $\mathrm{D}$ zones according to the XRD patterns in Fig.8 and Fe-Al phase diagram.

Figure 9 shows SEM image of Mn-added joint. As compared to no-added joint, microstructural morphologies seem to be unchaged, but aluminum molten pool seems to be expanded, and thickness of IMCs is about $12 \mu \mathrm{m}$, as shown in Fig.9a. When P2 zone in Fig.9a is magnified, IMCs can still be divided into three layers, as shown in Fig.9b. The interfacial microstructures at P3 zone are shown in Fig.9c. It appears the interfacial reaction occurrs there with the formation of IMCs. To determine the phase compositions of these IMCs, XRD and EDS are also performed. Three IMCs of $\mathrm{Fe}_{3} \mathrm{Al}_{2}, \mathrm{FeAl}_{2}$ and $\mathrm{Fe}_{2} \mathrm{Al}_{5}$ are formed, while some phases including $\mathrm{Mn}$ element are not seen at the reaction zones based on the analysis of XRD patterns in Fig.10. From the EDS results at F-O zone in Fig.9b and 9c listed in Table 2, it can be seen that the $\mathrm{Fe} / \mathrm{Al}$ ratio at $\mathrm{G}, \mathrm{H}$ and $\mathrm{I}$ zones are very close to $3: 2,1: 2,2: 5$, respectively. It is comfirmed that the layer at G-H zone are composed of $\mathrm{Fe}_{3} \mathrm{Al}_{2}, \mathrm{FeAl}_{2}$ and $\mathrm{Fe}_{2} \mathrm{Al}_{5}$. On the other hand, at interfacial zone, such as $\mathrm{M}$ and $\mathrm{N}$ zone in Fig.9c, the element compositions are close to the parents of dual phase steel, while the Fe/Al ratio at $\mathrm{L}$ and $\mathrm{O}$ zones are very close to $1: 1,1: 3$, respectively, thus, it is estimated that the IMCs in the corresponding zone are $\mathrm{FeAl}$ and $\mathrm{FeAl}_{3}$.

Figure 11 shows the microstructures of Si-added joint. It is evident that welding penetration depth increases compared with that of no-added joint, and thickness of 
IMCs is about 9-10 $\mu \mathrm{m}$, as shown in Fig.11a. When P4 zone in Fig.11a is magnified, it is found that IMCs is also divided into three layers (Fig.11b). The interfacial microstructures at the P5 zone are shown in Fig.11c. Similarly, the interfacial reaction can occurr which leads to the formation of IMCs. According to XRD patterns in Fig.12, IMCs of $\mathrm{FeAl}_{3}, \mathrm{FeAl}_{2}, \mathrm{Al}_{4.5} \mathrm{FeSi}, \mathrm{Al}_{0.5} \mathrm{Fe}_{3} \mathrm{Si}_{0.5}$ and $\mathrm{Al}_{9} \mathrm{Fe}_{2} \mathrm{Si}_{2}$ are formed at the reaction zones. Grounded on the EDS results at P-R zone in Fig.11b listed in Table 2, it is found that the Fe/Al ratio at $\mathrm{P}, \mathrm{Q}$ and $\mathrm{R}$ zones are very close to $1: 1,1: 2,1: 3$, respectively. Thus, it is thought that the layer at P-Q zone are composed of FeAl, $\mathrm{FeAl}_{2}$ and $\mathrm{FeAl}_{3}$. At interfacial zone, such as $\mathrm{S}, \mathrm{T}$ and $\mathrm{V}$ zone in Fig.11c, the element compositions are close to the parents of dual phase steel, while the Fe/Al ratio at $\mathrm{U}$ zone is very close to $3: 2$, hence, IMCs at $\mathrm{U}$ zone should be $\mathrm{Fe}_{3} \mathrm{Al}_{2}$.

To investigate elemental distribution of joints with/without powders, EDS linear scaning is performed, as shown in Fig.13, Fig.14,Fig.15, respectively. The elemental distribution of steel and aluminum molten pool are investigated by scanning lines 1 and 2. It can be seen that the contents of $\mathrm{Fe}$ and $\mathrm{Al}$ both change drastically in steel molten pool (Fig.13b and Fig.13c). This indicates that liquid Al rise and mix into the fusion zone with no powder. However, in the case of adding Mn powder, it is not obvious for the change of $\mathrm{Fe}$ and $\mathrm{Al}$ contents in steel molten pool(Fig.14b), and the distribution width of $\mathrm{Al}$ element in aluminum molten pool increases compared with that of no powder (Fig.14c), which is probably caused by the blockage effect of Mn powder as interlayer. When Si powder is added, the mixture of Fe and $\mathrm{Al}$ is both found in upper and lower molten pool (Fig.15b and Fig.15c), which indicates that the 
liquidity and metallurgical reaction of of molten pool can be improved.

\subsection{Hardness test of joints}

The measurements of the hardness distributions in the cross-sections of welding joint of specimen are implemented, and the hardness is measured 3-5 times in each area, then the average is taken as the test results. Hardness distribution of steel side is shown in Fig.16. It is found that the highest hardness values appears in HAZ, and the hardness value is higher than that of the base metal, thus softening phenomenon does not appear in HAZ, which has be explained by phase distribution and content of steel/aluminum weld zone(Fig.4). Figure 17 shows the hardness variation at three different penetration levels. It can be seen that the overall change trend is not obvious for the hardness in the weld. EDS are performed for the weld in order to analysis the hardness change, detection positions of the weld are shown in Fig.18, and the results are listed in table 3. It is found that the higher the Fe relative content is, the lower the hardness is. What is more, when the higer hardness is obtained, meanwhile, the higer Al relative content are observed, which is consistent with the results from Chen et al.[13]. Here, it should be pointed out that when Mn powder is added, the Al relative content upper the molten pool is lower than that of no powder, thus the Al element diffusion is suppressed from the lower to the upper.

\subsection{Shear test of welding joints}

Figure 19 shows the tensile-shear strength of joints with/without powders. It can be seen that the strength of Si-added joint which is $108 \mathrm{~N} / \mathrm{mm}$ is a little higher than that of Mn-added one that is $104 \mathrm{Mpa}$, and the strength of both joints exceeds that 
of no-added joint. Further inspection is performed on the fracture surfaces shown in Fig.20. It is found that the fracture surface of no-added or Mn-added joint shows a rivers shape pattern, which shows typical brittle fracture features. However, the fracture surface of Si-added joint displays microscale toughening nest and a small amount of inclusions, which is quasi-cleavage fracture, suggesting that the joint owns certain plasticity. Thus, the plasticity of Si-added joint is better than that of no-added or Mn-added one.

The addition of Mn or Si powders into the joint of DP590 dual phase steel to 6016 aluminum alloy improves tensile-shear strength of joints. It is well known that mechanical properties of joints are closely related to morphology and distribution of microstructures, especially to that of IMCs phase in the joints. In the present study, the decreased IMCs thickness is found in both Mn- and Si-added joints. This indicates the formation of brittle IMCs is suppressed effectively, which is benefit for the improved properties of the joints. In addition, the blockage effect of Mn powder as interlayer is seen in Fig.9 and Fig.14, because EDS analysis of IMCs in the joint indicates that $\mathrm{Mn}$ is not involved in metallurgical reaction with Fe or Al. Neverthless, small amount of liquid Al is mixed into steel molten pool, and the Al content increase in both sides of the weld, which leads to the increased weld width in aluminum molten pool. Thus, transverse area increase in jointing steel to aluminum, which is significant for the improved tensile-shear strength of joints[17]. As far as adding Si powder is concerned, it is not the case, the regulation effect of Si powder can be seen in Fig.11 and Fig.15, and the enhancement of the joint properties benefits from 
improvement of metallurgical reaction. The $\mathrm{FeAl}$ phase transforms into $\mathrm{Al}_{4.5} \mathrm{FeSi}$, $\mathrm{Al}_{0.5} \mathrm{Fe}_{3} \mathrm{Si}_{0.5}$ and $\mathrm{Al}_{9} \mathrm{Fe}_{2} \mathrm{Si}_{2}$ after $\mathrm{Si}$ powder is added. The phases $\mathrm{Al}_{4.5} \mathrm{FeSi}$ and $\mathrm{Al}_{9} \mathrm{Fe}_{2} \mathrm{Si}_{2}$ are similar to $\mathrm{Fe}_{2} \mathrm{Al}_{5}$ with regard to crystal structure, but $\mathrm{Fe}$ atom in lattice is replaced for $\mathrm{Si}$. The phase $\mathrm{Al}_{0.5} \mathrm{Fe}_{3} \mathrm{Si}_{0.5}$ is similar to $\mathrm{Fe}_{3} \mathrm{Al}$, but $\mathrm{Al}$ atom in lattice is replaced for Si. According to the $\mathrm{Fe}-\mathrm{Al}$ phase diagram, IMCs of $\mathrm{Fe}_{3} \mathrm{Al}, \mathrm{FeAl}, \mathrm{FeAl}_{2}$, $\mathrm{Fe}_{2} \mathrm{Al}_{5}$ and $\mathrm{FeAl}_{3}$ are easily formed. Among these, Fe-rich IMCs are recognised as ductile and tough phases while Al-rich IMCs are hard and brittle phases[9,10].Thus, formation of the IMC $\mathrm{Al}_{0.5} \mathrm{Fe}_{3} \mathrm{Si}_{0.5}$ with ductility and toughness is an important reason of enhancing mechancial proterties of the joint with Si powder, but the alloying of the IMCs is another way of improving the joint proterties that requires further investigation.

\section{Conclusions}

The following conclusions can be made concerning the effect of adding powder on joint properties of laser penetration welding for dual phase steel and aluminum alloy:

(1) some defects, such as spatter, inclusion, cracks and softening in heat affected zone (HAZ), can be avoided in welding joint, and the increased penetration depth is obtained by adding Mn or Si powder.

(2) The average tensile-shear strength of Si-added joint is $3.84 \%$ higher than that of Mn-added joint, and the strength of both joints exceeds that of no-added joint.

(3) In the case of adding Mn powder, small amount of liquid Al is mixed into steel molten pool, and the Al content increase in both sides of the weld, which leads to 
the increased weld width in aluminum molten pool. Thus, transverse area increases in jointing steel to aluminum, which is significant for the improved tensile-shear strength of joints. As far as adding Si powder is concerned, it is not the case, the enhancement of the joint properties benefits from improvement of metallurgical reaction.

\section{Acknowledgments}

The work was supported by National Science Foundation of China (51674112).

\section{References}

[1] G.Sierra, B.Wattrisse, C, Exp Mech 48(2008)212

[2] J.Fan, C.Thomy, F.Vollertsen, Physics Procedia A 12(2011)134

[3] C.Dharmendra, K.Rao, J.Wilden, S.Reich, Mater Sci Eng A 528(2011)1497

[4] J. Ma, M.Harooni, B.Carlson, R.Kovacevic, Mater Design 58 (2014)390

[5] G.Sierra, P.Peyre, F.Deschaux-Beaume, Mater Sci Eng A 447(2007)197

[6] H.Y.Lei, Y.B.Li, B.E.Carlson, Z.Q.Lin,Journal of Manufacturing Science and Engineering 137(2015)051028

[7] S.Bozzi, A.Helbert-Etter, T.Baudin, B.Criqui, G.Kerbiguet, Mater Sci Eng A 527(2010)4505

[8] L.Gerhard, B.Robert, I.Julia, E.Norbert, F.Gunter, B.Jürgen, P.Haris, P.Milan, H.Stefan, Physics Procedia A 12(2011)150

[9] M.J.Torkamany, S.Tahamtan, J.Sabbaghzadeh, Mater Design 31(2010)458

[10] H.C. Chen, A.J. Pinkerton, L. Li, Z. Liu, A.T. Mistry, Mater Design 32(2011)495

[11] Y.Shi, H.Zhang, W.Takehiro, J.Tang, Optics and Lasers in Engineering 48(2010)732

[12] D.W.Zhou, S.H.Xu, L.Peng, J.S.Liu,The International Journal of Advanced Manufacturing 
Technology 86(2016)2231

[13] S.H. Chen, J.H. Huang, K.Ma, X.K. Zhao, A.Vivek, Metallurgical and Materials Transactions A $45(2014) 3064$

[14] S.H. Chen, J.H. Huang, K. Ma, H.Zhang, X.K. Zhao, Mater Lett 79(2012)296

[15] X.D.Yang, Y. Shi, J. Liu, Journal of mechanical engineering 50(2014)143

[16] L.M .Liu, M.H. Chen, Optics and laser in engineering 51(2013)96

[17] M.Liu, J.B.Jiang,Journal of materials process technology 209(2009)2864 
Steel

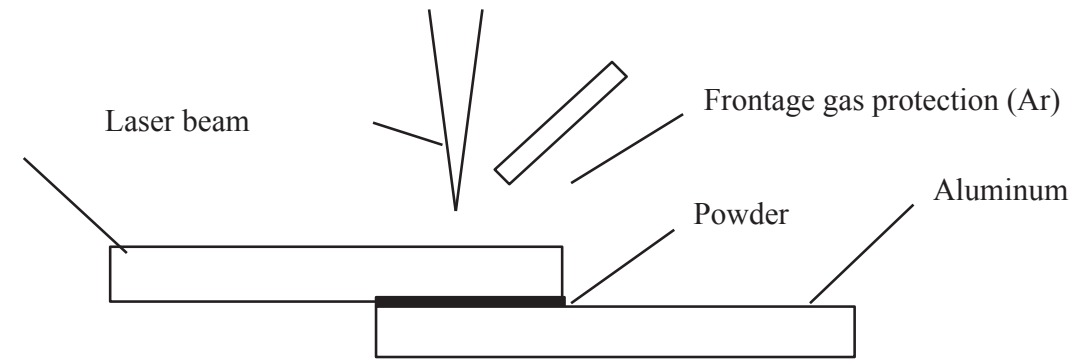

Fig.1 Schematic illustration of steel/aluminum welding set up 


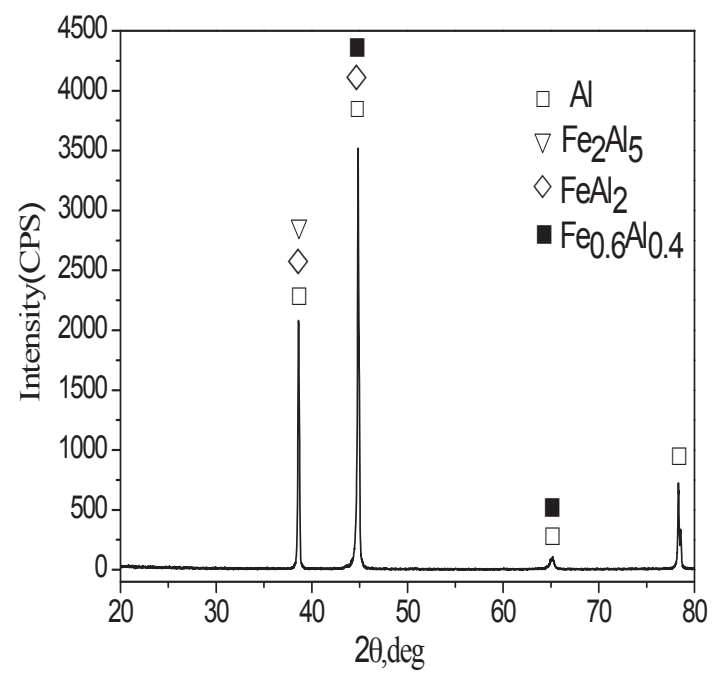

Fig.10 XRD patterns of Mn-added joints 

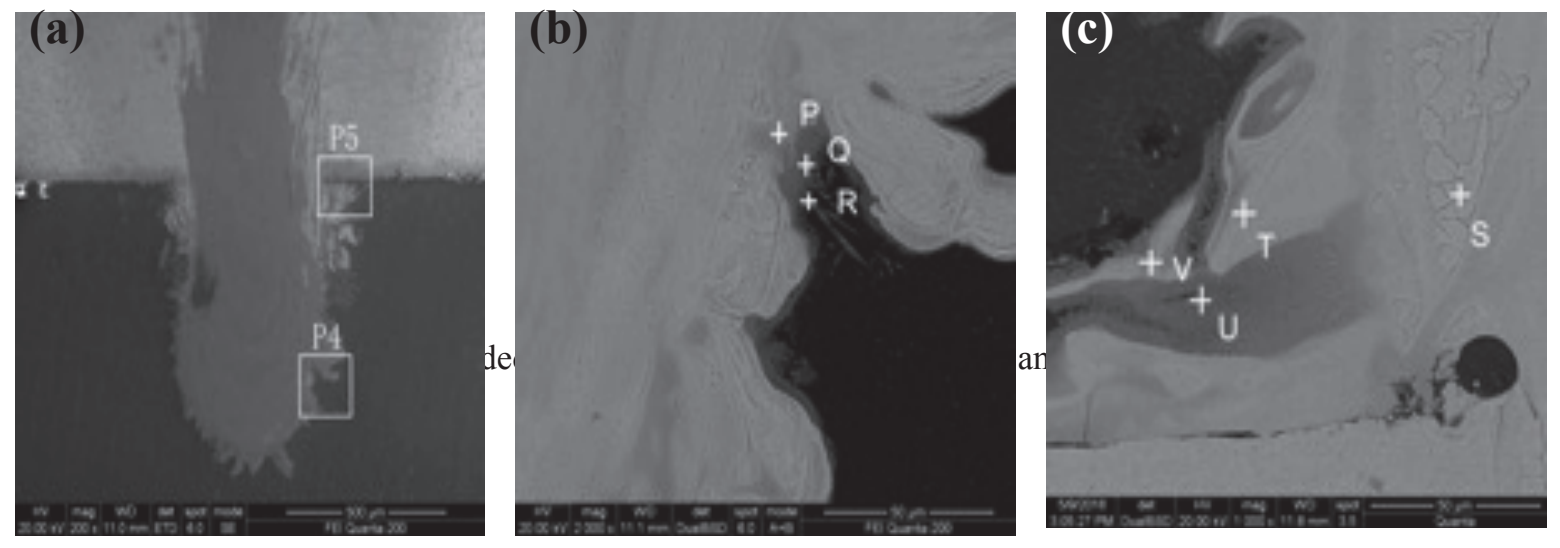


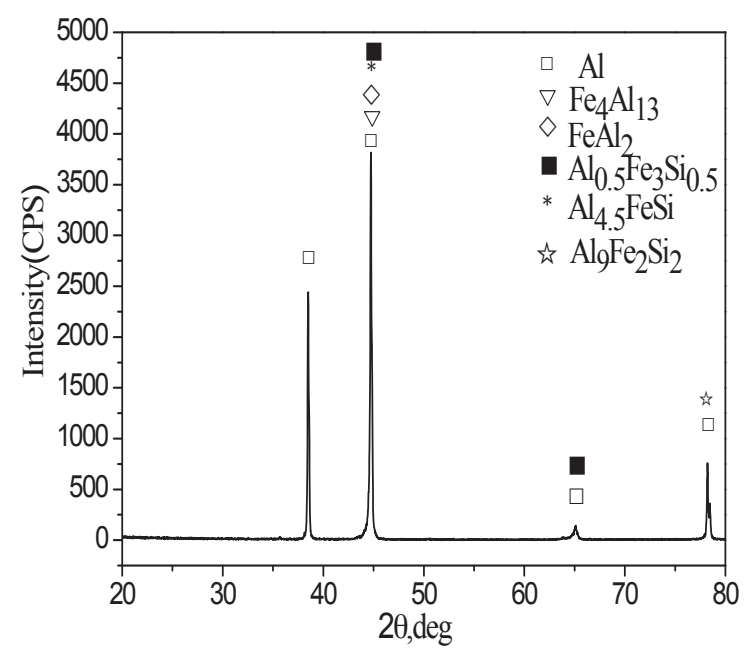

Fig.12 XRD patterns of Si-added joints 
Fig.13 EDS liner scanning of the elements distributions of No-added joints (a) scanning position, (b) and (c) scanning line I and

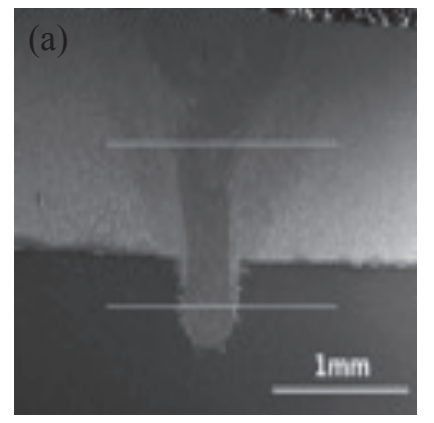

scanning line II in (a), respectively
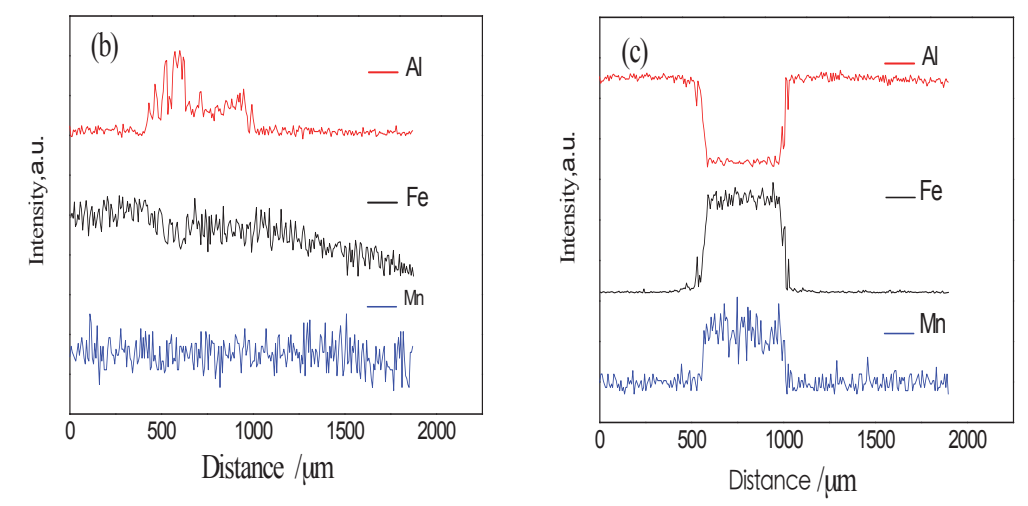
Fig.14 EDS liner scanning
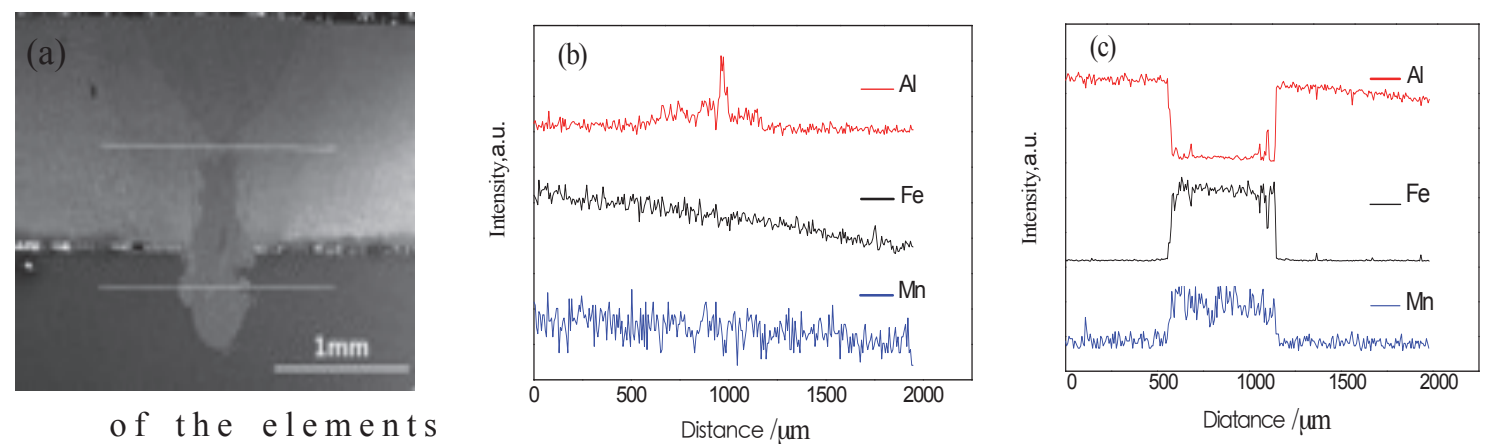

of the elements

distributions of Mn-

added joints (a) scanning position, (b) and (c) scanning line I and scanning line II in (a), respectively 
Fig.15 EDS liner scanning of the elements distributions of Si-added joints (a) scanning position, (b) and (c) scanning line I

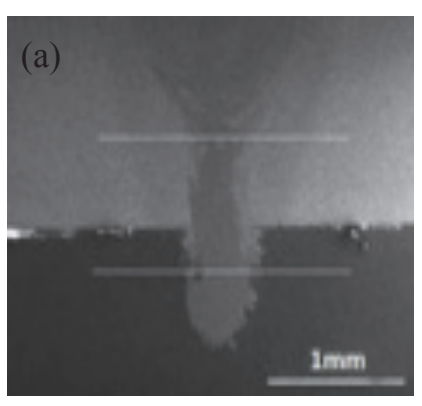

and scanning line II in
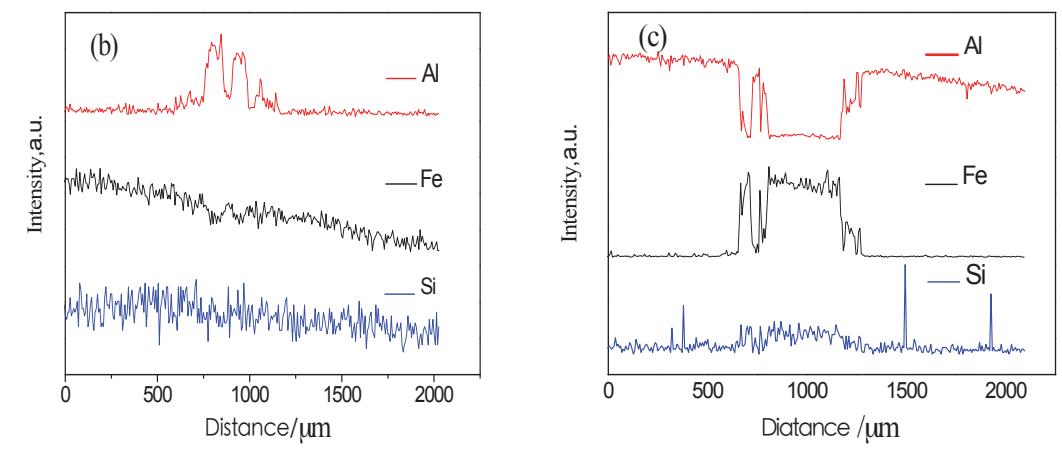

(a), respectively 
distribution of steel powder

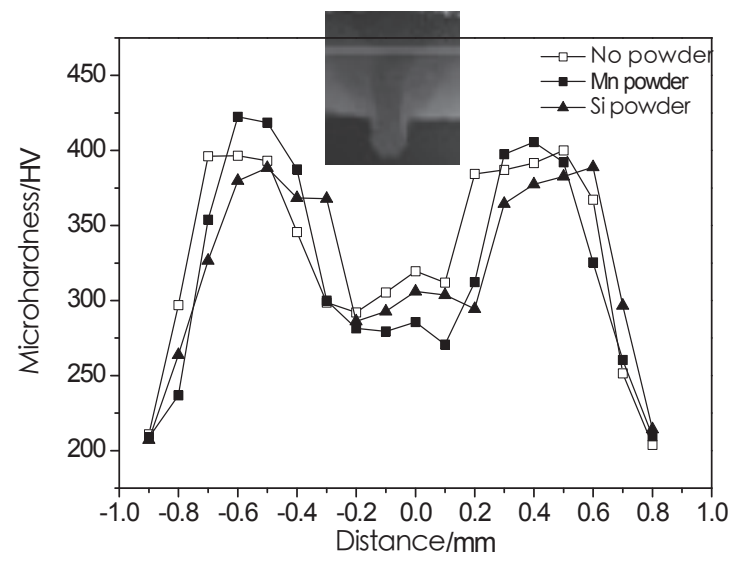

Fig.16 Hardness side with/without 


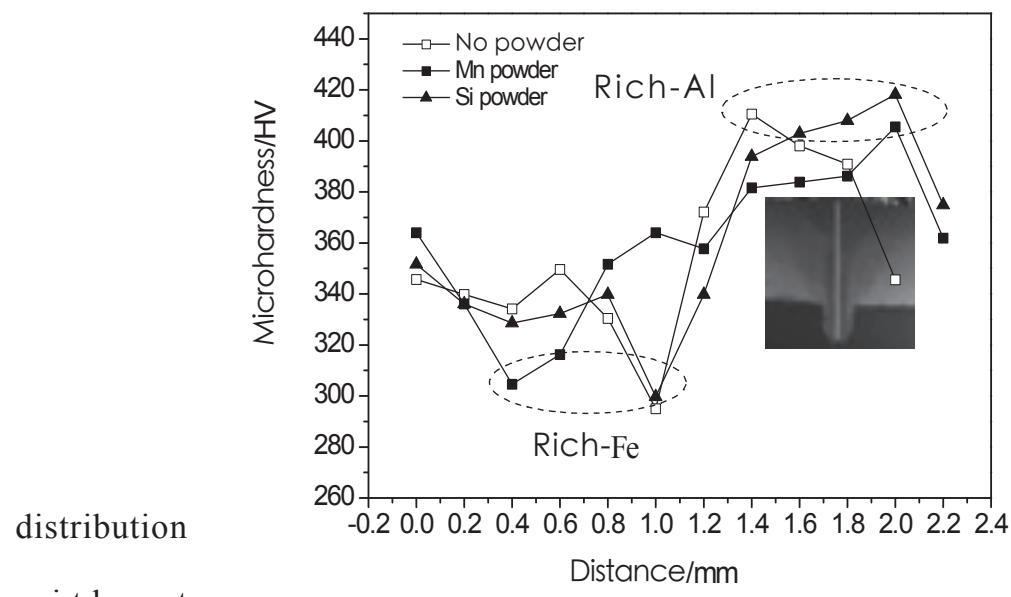

Fig.17 Hardness of penetration depth with/ powder 
Fig.18 Detection positions of the weld (a)No powder,(b) Mn powder and (c) Si powder

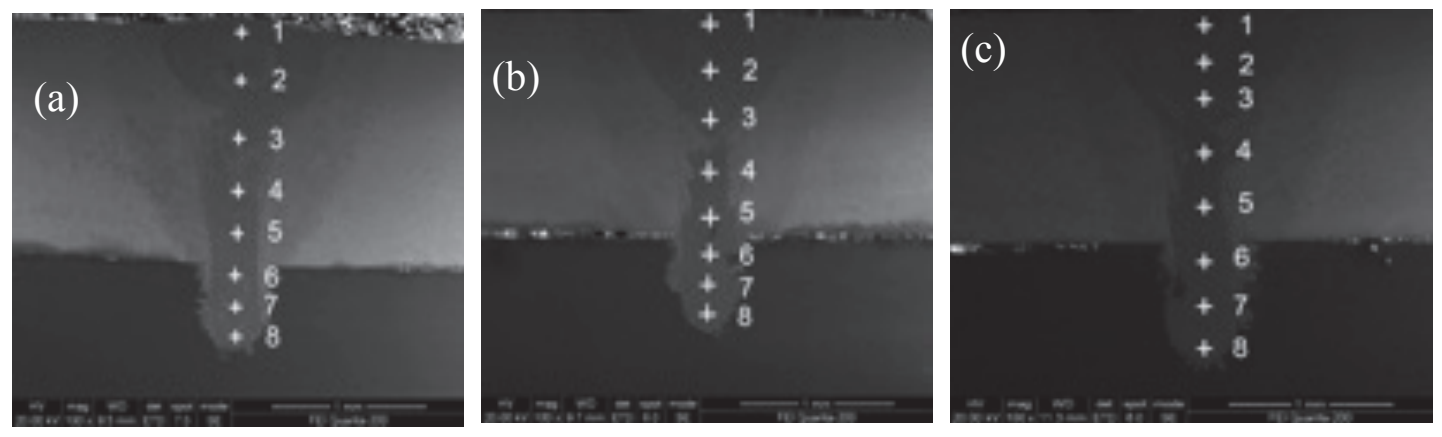




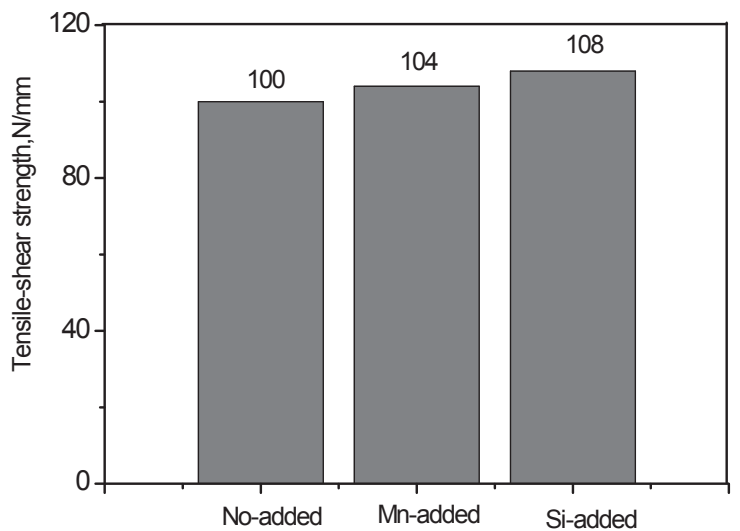

Fig.19 Tensile-shear strength of joints with/without powders 


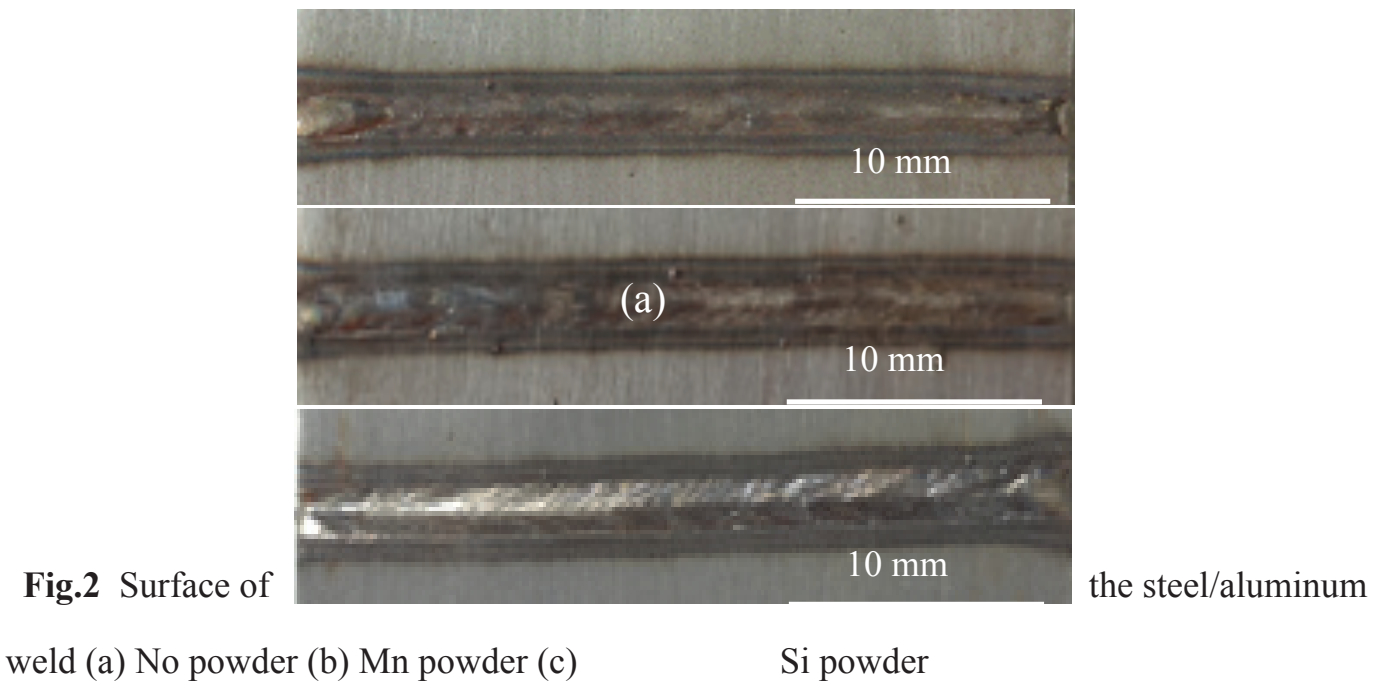



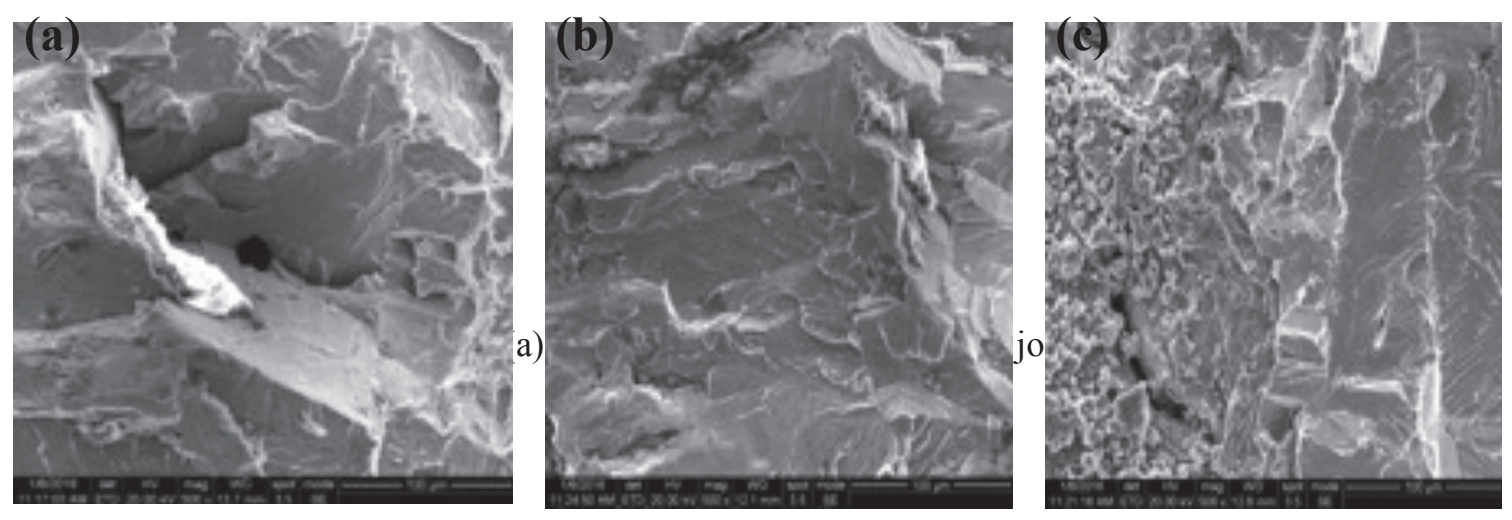


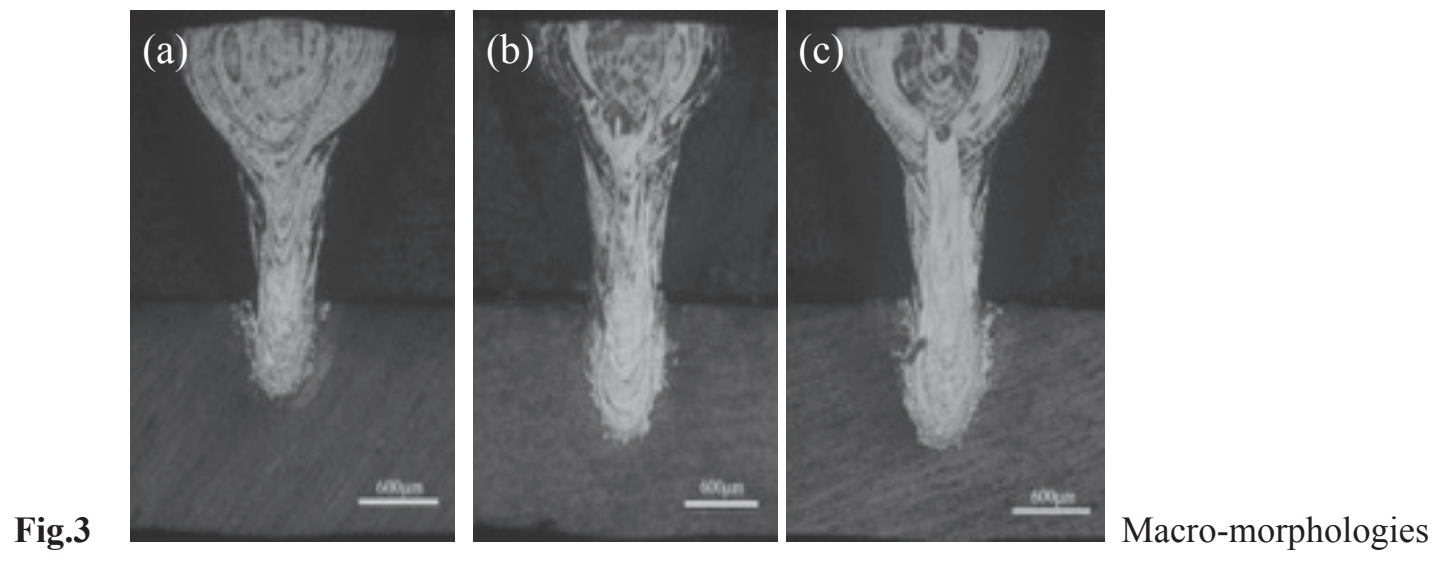

of weld cross section (a) No powder (b) Mn powder (c) Si powder 


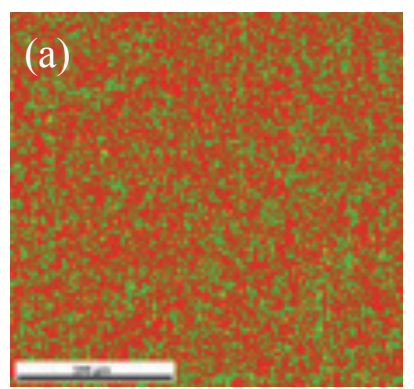

Toes Pantor $\frac{\text { Phase }}{\text { Fention }} \frac{\text { Frassen }}{0.545} \frac{\text { frastion }}{0.545}$

Martensibe $0.334 \quad 0.334$

Austoribe $0.021 \quad 0.021$

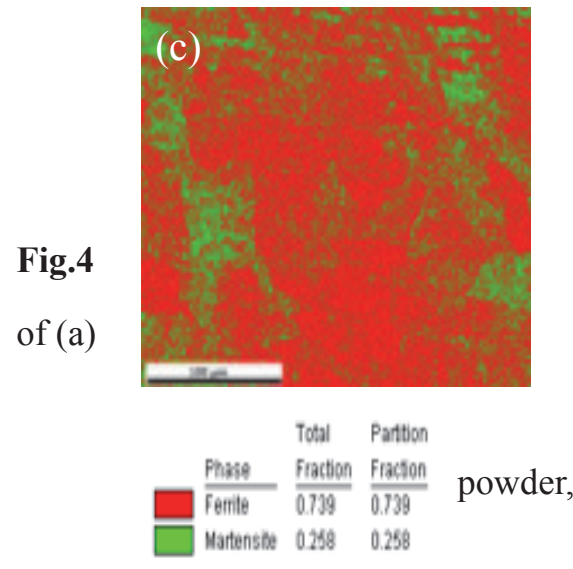

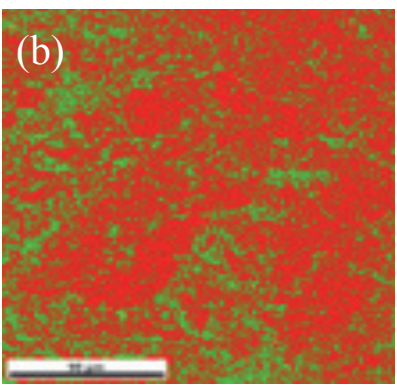

Toted Paston Fhase Fration fraction F6rile $\overline{0.721} \frac{\text { Find }}{0.718}$ Misting e.278 0278 Auburise ecot 0601

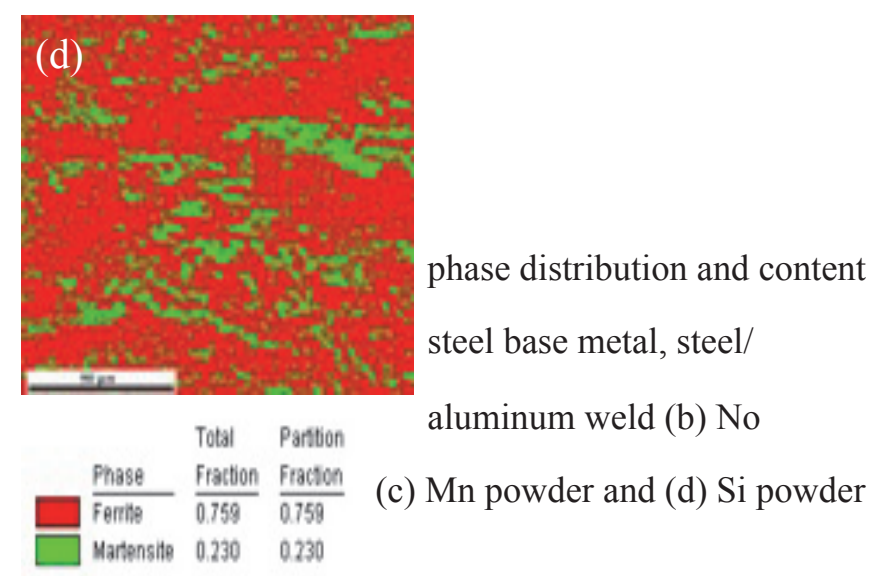



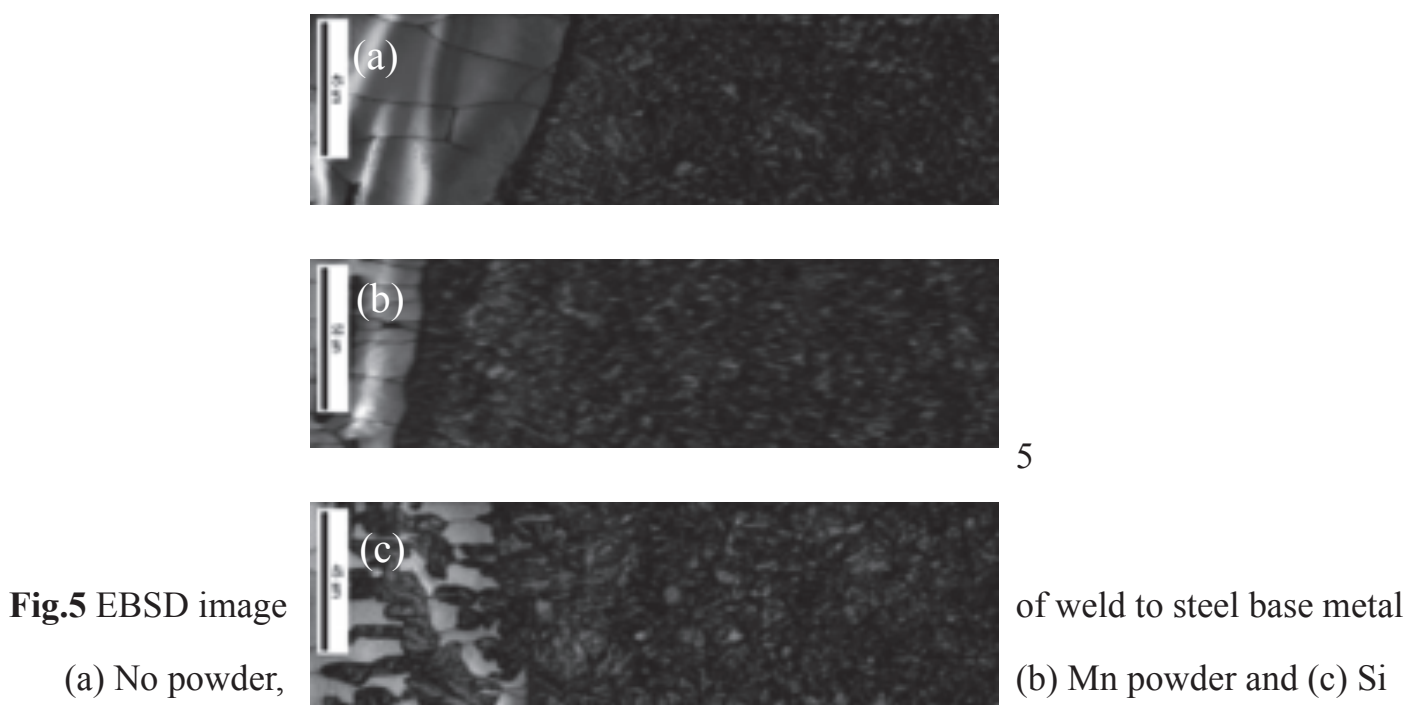
powder 


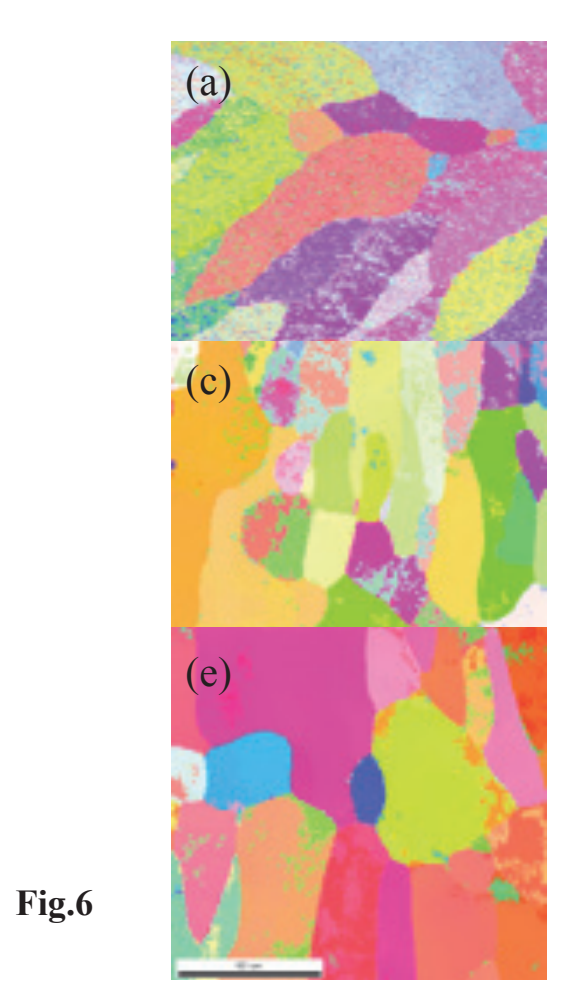

aluminum: (a)(b) No powder, (c)
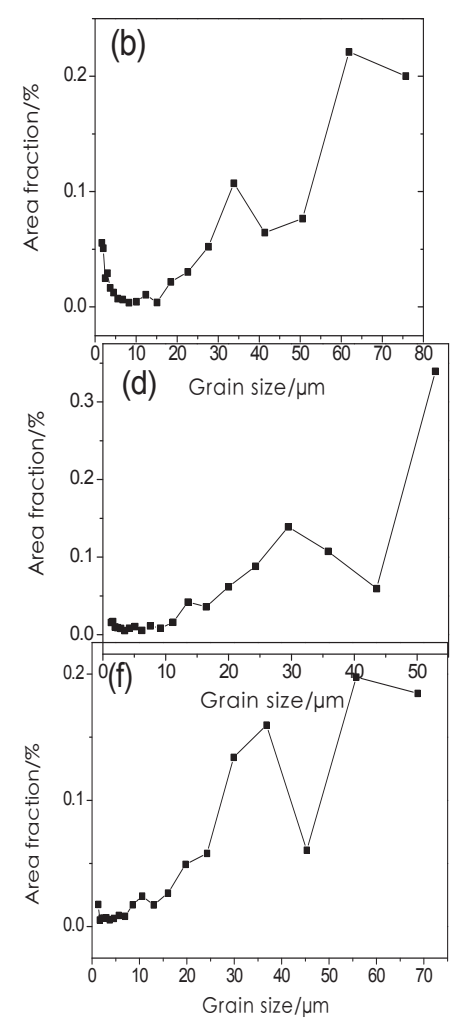

Grain size and distribution of steel/

(d) Mn powder and (e)

(f) Si powder 
Fig.7 Microstructure of No-added joints:(a)macro section cross, (b) magnification of P1 zone
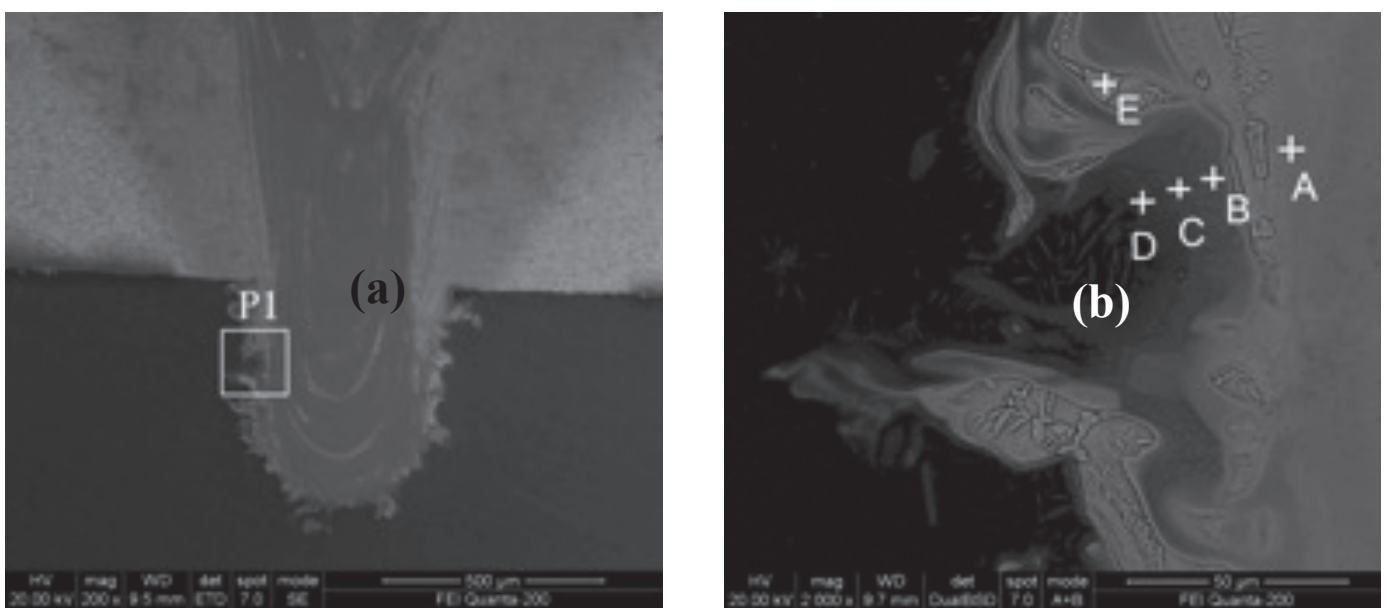


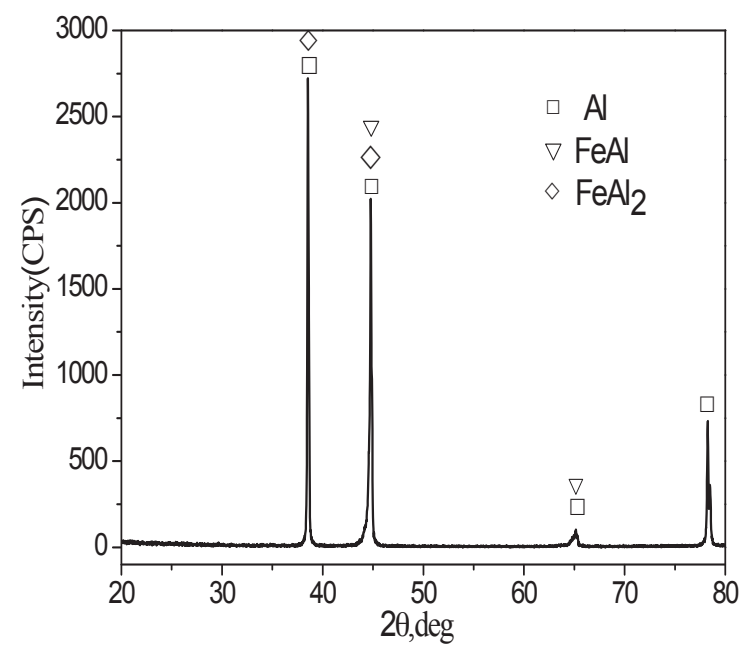

Fig.8 XRD patterns of No-added joints 

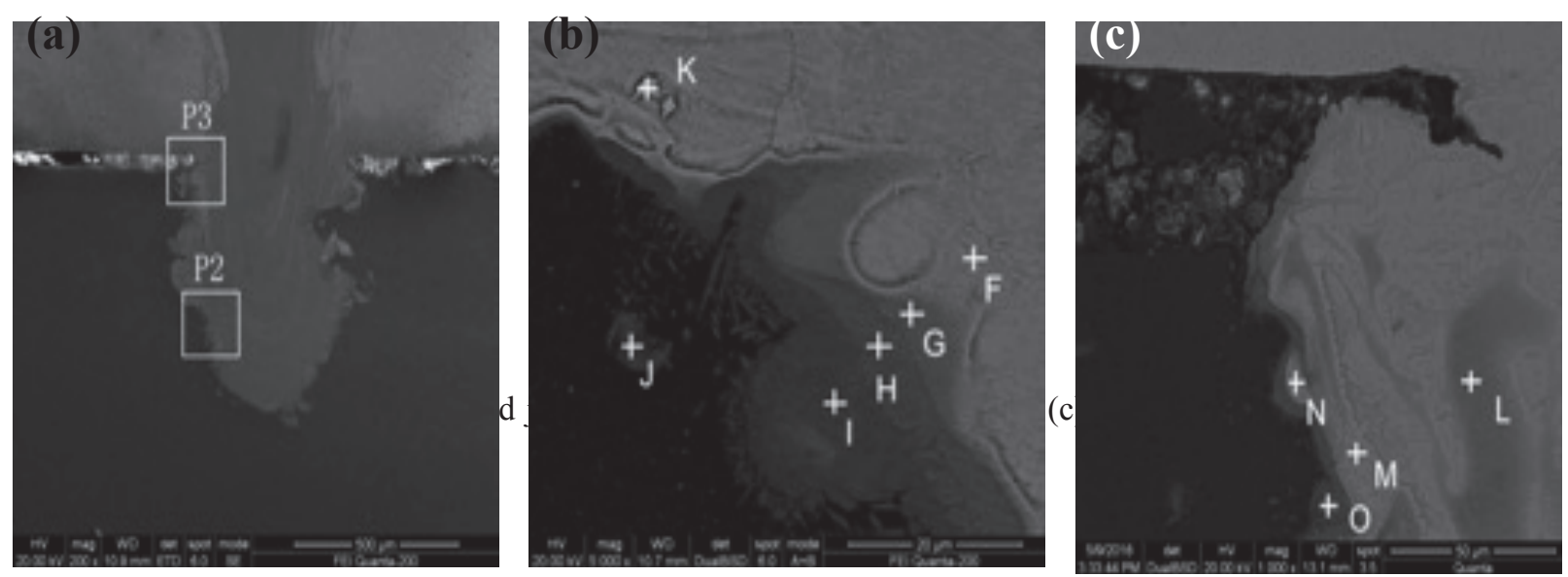
Table 1 Main technical parameters of fiber laser

\begin{tabular}{ccccccc}
\hline Parameter & $\begin{array}{c}\text { Laser powder/ } \\
\text { KW }\end{array}$ & Laser mode & $\begin{array}{c}\text { Angle alpha } \\
\text { of the beam } \\
\text { divergence } / \\
\text { rad }\end{array}$ & $\begin{array}{c}\text { Focal length } \\
\text { f/mm }\end{array}$ & $\begin{array}{c}\text { Focal spot d/ } \\
\mathrm{mm}\end{array}$ & $\begin{array}{c}\text { Wavelengt } \\
\mathrm{h}\end{array}$ \\
$\mathrm{N}$ & & $\mathrm{n} / \mathrm{nm}$ \\
\hline Value & $\leq 4.0(\mathrm{CW})$ & TEM $_{00}$ & $<0.15$ & 200 & 0.4 & 1070 \\
\hline
\end{tabular}


Table 2 EDS results at the reaction zone (at.pct)

\begin{tabular}{|c|c|c|c|c|c|}
\hline Element/zone & $\mathrm{Fe}$ & $\mathrm{Al}$ & $\mathrm{Mn}$ & $\mathrm{Si}$ & Phase \\
\hline A & 70.10 & 27.59 & 1.32 & 0.99 & unkown \\
\hline B & 83.72 & 13.31 & 1.77 & 1.21 & Fe-rich \\
\hline $\mathrm{C}$ & 43.52 & 55.28 & 0.93 & 0.27 & $\mathrm{FeAl}$ \\
\hline $\mathrm{D}$ & 36.19 & 62.81 & 0.74 & 0.25 & $\mathrm{FeAl}_{2}$ \\
\hline $\mathrm{E}$ & 83.70 & 9.16 & 1.67 & 1.87 & Fe-rich \\
\hline $\mathrm{F}$ & 73.96 & 22.34 & 2.83 & 0.88 & Fe-rich \\
\hline G & 58.49 & 38.54 & 1.99 & 0.99 & $\mathrm{Fe}_{3} \mathrm{Al}_{2}$ \\
\hline $\mathrm{H}$ & 35.83 & 62.50 & 1.26 & 0.41 & $\mathrm{FeAl}_{2}$ \\
\hline I & 27.24 & 71.76 & 0.84 & 0.16 & $\mathrm{Fe}_{2} \mathrm{Al}_{5}$ \\
\hline $\mathrm{J}$ & 18.39 & 80.68 & 0.76 & 0.18 & Al-rich \\
\hline $\mathrm{K}$ & 81.53 & 14.4 & 2.51 & 1.55 & Fe-rich \\
\hline $\mathrm{L}$ & 45.87 & 52.13 & 1.39 & 0.61 & $\mathrm{Fe}_{3} \mathrm{Al}_{2}, \mathrm{FeAl}_{2}$ \\
\hline M & 79.72 & 16.97 & 2.29 & 1.01 & Fe-rich \\
\hline $\mathrm{N}$ & 87.78 & 9.36 & 2.27 & 1.2 & Fe-rich \\
\hline $\mathrm{O}$ & 25.33 & 73.45 & 1.04 & 0.19 & $\mathrm{FeAl}, \mathrm{FeAl}_{2}$ \\
\hline $\mathrm{P}$ & 54.23 & 43.82 & 1.08 & 0.86 & $\mathrm{FeAl}$ \\
\hline Q & 34.88 & 63.72 & 0.89 & 0.51 & $\mathrm{FeAl}_{2}$ \\
\hline $\mathrm{R}$ & 22.94 & 76.63 & 0.43 & 0.0 & $\mathrm{FeAl}_{3}$ \\
\hline $\mathrm{S}$ & 90.1 & 5.97 & 1.94 & 1.99 & Fe-rich \\
\hline $\mathrm{T}$ & 70.3 & 26.26 & 1.57 & 1.8 & Fe-rich \\
\hline $\mathrm{U}$ & 27.15 & 68.49 & 0.62 & 3.74 & $\mathrm{FeAl}, \mathrm{FeAl}_{2}$ \\
\hline $\mathrm{V}$ & 58.66 & 38.37 & 1.61 & 1.35 & $\mathrm{Fe}_{3} \mathrm{Al}_{2}$ \\
\hline
\end{tabular}


Table 3 EDS results in the weld (at.pct)

\begin{tabular}{|c|c|c|c|c|c|}
\hline & Element/zone & $\mathrm{Fe}$ & $\mathrm{Al}$ & $\mathrm{Mn}$ & $\mathrm{Si}$ \\
\hline \multirow{8}{*}{$\begin{array}{c}\text { No } \\
\text { powder }\end{array}$} & 1 & 74.94 & 22.04 & 1.82 & 1.19 \\
\hline & 2 & 77.88 & 19.51 & 1.88 & 0.73 \\
\hline & 3 & 87.09 & 9.19 & 2.2 & 1.52 \\
\hline & 4 & 71.27 & 26.15 & 1.72 & 0.85 \\
\hline & 5 & 73.68 & 23.93 & 1.64 & 0.75 \\
\hline & 6 & 70.48 & 27.14 & 1.6 & 0.78 \\
\hline & 7 & 67.39 & 29.99 & 1.51 & 1.11 \\
\hline & 8 & 70.86 & 26.59 & 1.63 & 0.92 \\
\hline \multirow{8}{*}{$\begin{array}{c}\text { Mn } \\
\text { powder }\end{array}$} & 1 & 80.23 & 16.45 & 2.24 & 1.08 \\
\hline & 2 & 91.16 & 5.53 & 1.88 & 1.43 \\
\hline & 3 & 75.94 & 20.98 & 2.14 & 0.94 \\
\hline & 4 & 85.96 & 10.69 & 2.24 & 1.12 \\
\hline & 5 & 71.21 & 25.78 & 1.9 & 1.11 \\
\hline & 6 & 65.42 & 32.16 & 2.1 & 0.33 \\
\hline & 7 & 66.31 & 30.63 & 1.92 & 1.14 \\
\hline & 8 & 75.61 & 21.5 & 1.72 & 1.17 \\
\hline \multirow{8}{*}{$\begin{array}{c}\mathrm{Si} \\
\text { powder }\end{array}$} & 1 & 70.25 & 26.56 & 1.97 & 1.21 \\
\hline & 2 & 75.75 & 21.48 & 1.49 & 1.28 \\
\hline & 3 & 84.36 & 12.35 & 1.79 & 1.51 \\
\hline & 4 & 73.51 & 23.36 & 1.59 & 1.53 \\
\hline & 5 & 63.90 & 33.65 & 1.63 & 0.82 \\
\hline & 6 & 71.53 & 25.92 & 1.63 & 0.92 \\
\hline & 7 & 67.77 & 29.57 & 1.58 & 1.09 \\
\hline & 8 & 73.87 & 23.46 & 1.74 & 0.94 \\
\hline
\end{tabular}




\section{Graphical abstract}

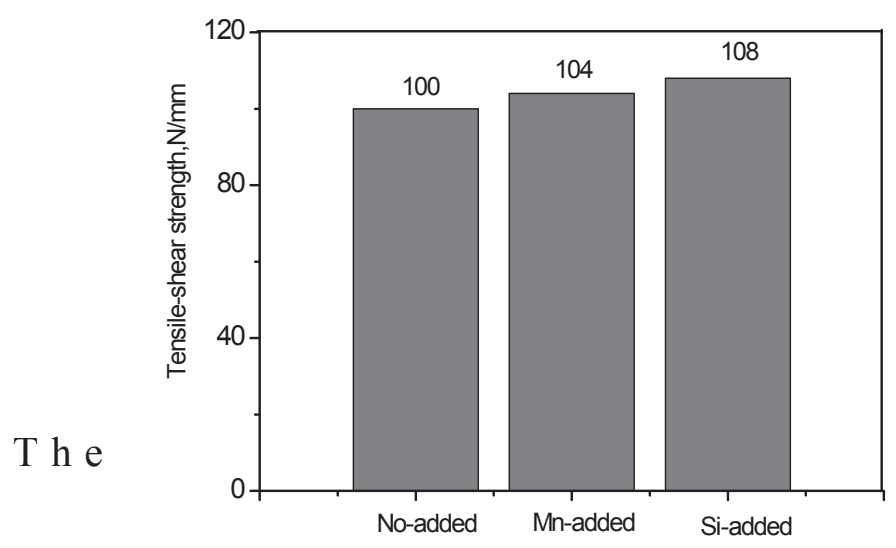

experiments of laser penetration welding for

dual phase steel and aluminum alloy were carried out, and the effect of adding Mn or Si powder on mechanical properties and microstructure of the weld was investigated. Some defects, such as spatter, inclusion, cracks and softening in heat affected zone (HAZ), can be avoided in welding joints, and the increased penetration depth is obtained by adding Mn or Si powder. The average tensile-shear strength of Si-added joint is $3.84 \%$ higher than that of Mn-added joint, and the strength of both joints exceeds that of no-added joint. In the case of adding Mn powder, small amount of liquid $\mathrm{Al}$ is mixed into steel molten pool, and the $\mathrm{Al}$ content increases in both sides of the weld, which leads to the increased weld width in aluminum molten pool. Thus, transverse area increases in jointing steel to aluminum, which is significant for the improved tensile-shear strength of joints. As far as adding Si powder is concerned, it is not the case, the enhancement of the joint properties benefits from improvement of metallurgical reaction. 